\title{
O Curso Comercial na formação intelectual ofertada pelas Associações Cristãs de Moços, no Brasil (1893-1929)
}

\author{
Anderson da Cunha Baía* \\ Andrea Moreno**
}

\begin{abstract}
Resumo
Este estudo procurou compreender a organização do Curso Comercial e seu propósito no projeto de formação intelectual das Associações Cristãs de Moços Brasileiras, no período de 1893 a 1929. Associação criada em 1844 na Inglaterra, inseriu-se no Brasil em 1893, no Rio de Janeiro, através do missionário norte-americano Myron A. Clark. Essa pesquisa trabalhou com panfletos, cartilhas, revistas, relatórios, atas e estatutos da instituição. Foi possível perceber que a formação intelectual foi parte integrante do projeto acmista. A oferta de ações que proporcionariam tal formação, em especial o Curso Comercial, foi realizada pela ACM como o principal curso que poderia contribuir com a ascensão social dos seus associados, especialmente ancoradas em argumentos relativos à utilização do tempo ocioso com coisas úteis. As ACMs atuaram, dessa forma, como um lugar de preparação, formando o associado para o trabalho, para novos hábitos, comportamentos e sensibilidades de uma formação intelectual acmista.

Palavras-Chave: história da educação; curso comercial; associação cristã de moços.
\end{abstract}

\section{The Commercial Course in intellectual formation offered by Young Men's Christian Associations, in} Brazil (1893-1929)

\section{Abstract}

This study aims to understand the organization of the Commercial Course and its purpose in the project of intellectual formation of the Young Men's Christian Associations Brazilian, from 1893 to 1929. Association created in 1844 in England, was inserted in Brazil in 1893, in Rio de Janeiro, by north American missionary Myron A. Clark. This research used periodicals, pamphlets, booklets, minutes and statutes of the institution. It was revealed that the intellectual formation was part of acmista project. The offering of shares that would provide such formation, in particular the Commercial Course was held by ACM as the main course that could contribute to the social advancement of its members, especially anchored in arguments relating to the use of idle time with useful things. The YMCAs acted thus as a place of preparation, forming the associate to work, to new habits, behaviors and sensitivities of a acmista intellectual formation.

Keywords: history of education; commercial course; young men's christian association

\section{Introdução}

A Associação Cristã de Moços (ACM) surgiu na Inglaterra, em meados do século XIX, por iniciativa de George Williams. As primeiras sedes inglesas da ACM foram criadas, especialmente, para contribuir na formação de jovens que presenciavam a Inglaterra em processo de industrialização. As condições precárias e a jornada extenuante de trabalho, agravadas pelo inchaço das cidades, que não conseguiam absorver toda mão de obra disponível, contribuíram para a criação de um quadro de degradação social que culminou com a Revolução Industrial (HOBSBAWN, 1986).

Sua entrada no Brasil aconteceu por intermédio de uma missão da Associação Cristã de Moços dos Estados Unidos (Young Men's Christian Association, YMCA), em 1891, quando chegou ao país o missionário norte-americano Myron Clark. O

\footnotetext{
*Endereço eletrônico: andersonbaia@yahoo.com.br

*** Endereço eletrônico: andreafaeufmg@gmail.com
}

missionário cria as ACMs do Rio de Janeiro (1893), Porto Alegre (1901) e São Paulo (1902). O propósito central do projeto de Clark, no Brasil, era promover o "desenvolvimento" do "caracter christão" dos associados da ACM e a "utilidade dos seus membros" assim como "promover o bem physico, intellectual, social e espiritual dos moços" (ASSOCIAÇÃO CRISTÃ DE MOÇOS, 1893, p. 02). Assim, o projeto de formação das Associações Cristãs de Moços alicerçava suas ações no princípio de formação intelectual, moral-religiosa e física.

$O$ foco desse estudo é a formação intelectual, especificamente o Curso Comercial, no período de 1893 a $1929^{1}$. A Instituição ofertava um conjunto de ações referentes ao que a Associação Cristã de Moços chamava de "formação intelectual": curso de Ensino Primário, Curso Comercial, Curso Preparatório, Aulas Avulsas, Biblioteca, Sala de Leitura, Conferências Populares, 
Grupos de Estudos. Devido a centralidade do Curso Comercial no projeto de formação intelectual da instituição, buscamos compreender como o curso Comercial estava organizado e qual seu propósito no projeto de formação intelectual das Associações Cristãs de Moços Brasileiras.

Para dar conta desse estudo, apoiamos em Certeau (2006, p.81), para quem em história tudo começa com o gesto de separar, reunir e transformar em documentos certos objetos distribuídos de outra maneira. O Curso Comercial, como uma das ações da formação intelectual, foi tomado como eixo e ponto de partida, direcionando-nos, na procura pelos documentos necessários a esta pesquisa: à Biblioteca Nacional, no Rio de Janeiro; à Federação Brasileira das ACMs, em São Paulo; ao Centro de Memória do Esporte, na Universidade Federal do Rio Grande do Sul (UFRGS), em Porto Alegre; e às diferentes sedes acmistas do Brasil, que foram implantadas no período estudado e ainda estão em atividade. Acessamos panfletos, cartilhas, relatórios, atas e estatutos das diferentes sedes acmista; no entanto, uma importante fonte para esse estudo foi o periódico Mocidade: Revista Mensal das Associações Christãs de Moços no Brasil, que como "órgão oficial das Associações Cristãs de Moços no Brasil", que funcionou como um instrumento estratégico na circulação de objetivos, métodos, saberes e práticas que diziam da constituição do esporte na instituição.

\section{A formação intelectual e o discurso da ascensão social}

Nos momentos de implantação da ACM no Brasil, não havia uma comissão específica para promover a chamada "formação intelectual" dos associados. Essa tarefa ficou a cargo da Comissão de Divertimentos até início do século XX. Alterações aparecem a partir dos Estatutos das ACMs de Porto Alegre (1901) e do Rio de Janeiro (1907), quando se cria uma "Comissão de Instrução".

Essa Comissão, ao incorporar a organização das aulas noturnas separada do divertimento, indica uma valorização das atividades intelectuais ao receber uma estrutura administrativa específica para pensar a organização das ações de formação intelectual. A instituição ofertava o curso de Ensino Primário, Curso Comercial, Curso Preparatório, Aulas Avulsas, Biblioteca, Sala de Leitura, Conferências Populares, Grupos de Estudos².

Uma necessidade da Comissão de Instrução era a de pensar sobre as formas de conquistar seu público alvo. $\mathrm{Na}$ instituição, a maior parte dos associados era "empregado do commercio, e, portanto, moços privados de escholas" (CLARK, 1903, p. 51). Assim, as diferentes atividades intelectuais passaram a ser, para o projeto acmista, uma oportunidade de ocupar as horas vagas dos jovens com a oferta de "matérias úteis" para seu progresso no trabalho. Estrategicamente, com a ocupação desse tempo ocioso do associado, a instituição afastava-o dos "perigos mundanos" e, ao mesmo tempo, disponibilizava a instrução necessária à sua incorporação no projeto acmista.

Diz Samuel Smiles, notavel escriptor inglez: "Estamos diariamente expostos às tentações da preguiça, da indulgencia e do vicio. Pelo sentimento de dever, e pela força da coragem, incumbe resistir a estas cousas, embora com sacrificio de interesses mundanos". Si cedermos a essas tentações, continuaremos sempre a receber ordens; si resistirmos, e empregarmos as horas vagas em fins uteis, ha probabilidade de subirmos na escala do trabalho até chegarmos à posição de dar ordens. Para o estudo das linguas, das sciencias, dos principios, regras e praticas de qualquer profissão, não é necessario cursar academias, basta o emprego util $e$ perseverante das horas vagas (ASSOCIAÇÃO CRISTÃ DE MOÇOS, 1910, p. 01).

Ao focar no público trabalhador, com atividades no seu contraturno, a instituição investia no controle racional do tempo do Associado. A meritocracia que encampava o discurso da instituição aponta para a necessidade de o indivíduo autocontrolar-se, afastando-se dos "prazeres do mundo" e entregando-se ao projeto de formação da ACM. Era uma escolha pessoal, de valorização da liberdade, a qual representava uma liberdade guiada pelos princípios da instituição. Ao se inserir na Associação, a formação intelectual seria um dos "remédios" a ser administrado por ela aos trabalhadores, nos momentos de folga deles. Com "empenho", o associado instruído estaria apto a ocupar melhores posições no emprego. Nesse cenário, o Curso Comercial adquire centralidade pela sua especificidade na formação para atuar no comércio.

Ao se referir à educação como instrumento de ascensão social, Souza (1992) afirma que a construção de uma atmosfera ideológica em torno dela apontou-a como elemento de equalização social com base no mérito dos indivíduos. O sucesso dependeria, eminentemente, do esforço de cada um. 
Assim, enquanto os educadores e reformadores sociais viam na educação um poderoso instrumento de regenerar a república e promover a modernização do país, as camadas populares viam-na como um meio de ascensão social e melhoria da qualidade de vida.

No discurso acmista, entrar nesse mundo da instrução, do aprofundamento nos estudos, especialmente para os trabalhadores, era uma premissa para se conseguir uma ascensão social no emprego.

Para o empregado no commercio, na fabrica ou na officina, nada pode haver de mais importancia do que aproveitar-se das suas horas vagas. Depois de fechado o estabelecimento em que trabalha, elle deve entregar-se a estudos que sejam de utilidade, adquirindo conhecimentos que o habilitem a melhorar de posição e merecer augmento de ordenado (ASSOCIAÇÃO CRISTÃ DE MOÇOS, 1910, p. 07).

Thompson (2002), ao tratar da educação de jovens, ressalta que a ascensão social por meio da instrução se materializaria às custas de uma conformação dos estudantes. O autor afirma que, no século XIX e início do século XX, a educação não era apenas uma baliza na direção de um novo universo mental e mais amplo mas também uma baliza para longe, para fora do mundo da experiência. O campo da instrução exigia uma rejeição e um desprezo pela linguagem, costumes e tradições da cultura popular. Assim, o trabalhador que dedicava suas noites e seus domingos à busca de conhecimento era também solicitado a rejeitar todo o cabedal humano de sua infância e de seus companheiros trabalhadores. A educação formal escolar direcionava a incorporação de novos atributos de autodisciplina e autorrespeito, com propósito de adequar os trabalhadores ao estilo de vida e aos hábitos mentais da classe média.

A Associação Cristã de Moços no Brasil estava sintonizada com esse debate educacional. Esse assunto era um dos temas emergentes no período republicano, como mostra Souza (1992), no estudo Demandas populares pela educação na Primeira República: aspectos da modernidade brasileira, e fazia parte dos interesses formativos acmistas. Para a Associação: "[...] numa República a educação é uma necessidade primordial" (ASSOCIAÇÃO CRISTÃ DE MOÇOS, 1916, p. 05). Nessa perspectiva, a ACM projetava a formação de um indivíduo que pudesse contribuir com o engrandecimento da pátria. Para isto, a educação era apenas uma das frentes de formação que, com as ações envolvendo a moral-religiosa e a formação física, completavam as ações centrais da proposta acmista.

Nesse movimento de moldar o associado por meio da formação intelectual, a Associação Cristã de Moços colocava-se como uma instituição que ocupava uma "posição muito humilde entre as instituições de educação na capital" (ASSOCIAÇÃO CRISTÃ DE MOÇOS, 1918a). Utilizou-se do Curso Comercial como forma de contribuir com a melhoria da posição do associado no emprego, ascendendo-o de cargo ${ }^{3}$.

O discurso acmista enfatizava o "perigo" que rondava a vida da mocidade nos momentos de ociosidade. Entre uma jornada de trabalho e outra, havia um conjunto de atividades do cotidiano que poderiam, na concepção da instituição, desviar o jovem de uma vida cristã (ASSOCIAÇÃO CRISTÃ DE MOÇOS, 1918a). Era necessário um investimento na racionalização do cotidiano. Reconhecia-se que o jovem tinha desejos e instintos, logo a função da ACM era a de mostrar a ele os caminhos para controlá-los, sendo as aulas noturnas, como o Curso Comercial, uma das formas de substituição das atividades consideradas, pela instituição, "impróprias" pelas atividades "úteis".

Envolvida pela ideia de que os moços deveriam manter-se ocupados nos momentos de folga, a ACM planejava-se para: "[...] oferecer aos moços um lugar onde eles podem passar horas da noite, anteriores ao sono, em distração inofensiva, convivência edificante e ocupação proveitosa" (ASSOCIAÇÃO CRISTÃ DE MOÇOS, 1918a, p. 02). Como, para o projeto acmista, o associado dificilmente ascenderia no trabalho se não estivesse preparado para resistir às "tentações" do cotidiano, as ações da Comissão Intelectual eram algumas das formas utilizadas para ajudá-lo no controle do corpo, dos instintos e da racionalização do tempo.

Não havia uma garantia, por parte da instituição, de que, aproveitando as horas vagas para se dedicar aos estudos, o indivíduo começasse a "dar ordens", ao invés de "receber ordens". Mas, fazia parte do discurso acmista que uma boa formação intelectual era um poderoso instrumento de ascensão social. Souza (1992), embora considere que esse não era o único caminho, afirma que a educação possibilitava, no início do século $\mathrm{XX}$, condições reais, ainda que limitadas, de ascensão social. Assim, para as camadas populares, a educação poderia estar articulada com o projeto de melhoria das condições de vida, oferecendo 
condições para o exercício de atividades de maior prestígio, de caráter não manual, como: o serviço público, o trabalho em escritórios, as carreiras políticas e liberais.

Nesse processo de formação do associado, a ACM colocava-se como mediadora entre o indivíduo "sem rumo" e o caminho para a regeneração dele. Um material produzido pela ACM, intitulado "Bom emprego para o Jovem Ambicioso" que circulou pelas diferentes sedes, informava que a aquisição de bons empregos dependia do preparo do candidato, sendo que o sucesso ou o fracasso dependeriam do uso que cada um fizesse de suas oportunidades (ASSOCIAÇÃO CRISTÃ DE MOÇOS, 1911).

Portanto, caberia ao aluno, a partir da sua escolha, procurar a ajuda da Associação, sendo ela uma portadora das oportunidades, dentre as quais, o curso Comercial era compreendido pela mesma como uma das formações mais apropriadas para a ascensão social.

\section{O Curso Comercial: um preparo para as posições mais altas}

Ser alfabetizado era o passo inicial para os indivíduos que decidissem aprofundar na sua formação. O Curso Comercial, nos qual se destacavam a formação em guarda-livros ou estenografia, era uma das ações que as ACMs ofertavam para os associados que se interessassem em dar prosseguimento ao Ensino Primário ${ }^{4}$. Segundo Veiga (2007), no Rio de Janeiro e em São Paulo, em fins do século XIX, já havia oferta de cursos profissionalizantes, dentre eles: o comercial, o de desenho e o de estenografia. Nas Associações Cristãs de Moços,

[...] os alumnos que quizerem obter o diploma de guarda-livros ou de stenographo escolherão respectivamente escripturação mercantil ou stenographia e dactylografia. Além dos exames prestados no fim do primeiro e segundo annos, deverá o candidato submetter-se ao cabo do terceiro anno do curso a um exame geral sobre as materias estudadas, dependendo do seu bom exito [terá] a posse do diploma (ASSOCIAÇÃO CRISTÃ DE MOÇOS, 1913, p. 06).

Para a instituição, o Curso Comercial correspondia ao oferecimento de uma formação voltada ao mercado de trabalho: "[...] especialmente em matérias práticas que o moço precisa na sua vida comercial" (ASSOCIAÇÃO CRISTÃ DE MOÇOS, 1898). Como a maior parte dos associados era empregado do comércio, com uma jornada de trabalho que ocupava grande parte do dia, as aulas do curso comercial, como aconteciam nas aulas do Ensino Primário, eram alocadas no período noturno ${ }^{5}$. O curso, dividido em três anos, apresentava a seguinte distribuição:

Quadro 1: Matérias do Curso Comercial

\begin{tabular}{c|c|c}
\hline \multicolumn{3}{c}{ Curso Comercial: guarda-livros ou estenografia } \\
\hline $1^{\text {o } \text { ano }}$ & $2^{\text {o } \text { ano }}$ & $3^{\text {o }}$ ano \\
\hline Português & Português & Português \\
Francês, Inglês ou Alemão & Francês, Inglês ou Alemão & Francês, Inglês ou Alemão \\
Aritmética & Aritmética & Rudimentos do Direito \\
Datilografia & Geografia & $\tilde{\text { Geografia }}$ \\
Escrituração Mercantil e & Escrituração Mercantil e & Escrituração Mercantil e \\
Caligrafia ou Estenografia & Caligrafia & Caligrafia \\
& Estenografia ou Datilografia & Estenografia ou Datilografia \\
\hline
\end{tabular}

Fonte: Adaptação de um quadro da ASSOCIAÇÃO CRISTÃ DE MOÇOS, 1913, [s.p.].

A organização das disciplinas reporta para uma formação em dois eixos: uma formação geral do indivíduo, representada pelo ensino das línguas portuguesa e estrangeira, e da geografia; e uma formação específica, com disciplinas de caligrafia, datilografia, escrituração mercantil, estenografia e direito comercial. Tanto a formação geral quanto a formação específica eram compostas por conteúdos que tinham, para o projeto acmista, uma aplicação prática no comércio, seja no atendimento ao cliente, seja na organização e na administração do estabelecimento. 
O Curso Comercial possibilitava também a formação em outras áreas além da função de guarda-livros e estenografia, como os cursos de correspondente e de gerente, ofertados pela Associação Cristã de Moços do Rio de Janeiro, ainda no final do século XIX ${ }^{6}$.

Em muitas Associações ha cursos elaborados para tres ou quatro annos e quando o socio completa o curso recebe um diploma que o habilita a exercer varios empregos como guardalivros, tachigrapho, correspondente, ou mesmo gerente, e algumas associações garantem collocação para os socios que completam o curso (ASSOCIAÇÃO CRISTÃ DE MOÇOS, 1898, p. 39).

No relatório da Associação Cristã de Moços do Rio de Janeiro, no ano de 1912, dentre os diversos serviços prestados pela instituição, pode-se observar o acolhimento e o encaminhamento dos indivíduos recém-chegados à cidade, a favor dos quais a ACM intercedia em prol de uma "colocação em alguma casa comercial", como empregado. Se o resultado dessa ação não fosse imediato, a Associação afirmava que "vintenas" conseguiram empregos por seu intermédio.

As ACMs propagavam a ideia de que havia posições boas que aguardavam os moços preparados, e que aquele moço que: “[...] deixa de se preparar não tem segurança mesmo numa posição superior" (ASSOCIAÇÃO CRISTÃ DE MOÇOS, 1918b, p. 10). Se o caminho da ascensão no trabalho era apontado pela instituição, a vontade de ter uma formação mais aprofundada deveria partir do associado, o qual, ao procurar a ACM, receberia dela "[...] os meios de ajudar o moço a achar um lugar que corresponde à sua competência, e facilitar aos patrões a descoberta de empregados competentes" (ASSOCIAÇÃO CRISTÃ DE MOÇOS, 1918b, p. 06). Competência que, no discurso acmista, era atestada pela instituição quando o associado completava um de seus cursos, especialmente aqueles do Curso Comercial, propagado como o indicado para preparar "o moço para as posições mais altas" (ASSOCIAÇÃO CRISTÃ DE MOÇOS, 1918b, p. 10).

$\mathrm{O}$ investimento institucional em prol de empregar os associados pode ser observado no relatório da Associação Cristã de Moços do Rio de Janeiro, apresentado na VII Convenção Nacional das ACMs, em 1929, no qual havia uma iniciativa de se criar uma Secção de Empregos, que, mesmo ainda em fase de organização, empregou, em 1925,
"40 moços". Ao empregar pessoas, a ACM possibilitava que esse público, ao começar a receber seus ordenados, ingressasse nas ações dela, contribuindo para a consolidação do seu projeto de formação. Quanto mais pessoas estivessem empregadas e quanto mais elas estivessem preparadas para ascender de função no emprego, seria melhor para a instituição, pois isso poderia influenciar diretamente no aumento da receita da instituição, seja no acréscimo de associados, seja no maior volume de donativos.

Ao pensar no Curso Comercial como um instrumento que possibilitaria ao associado melhorar sua posição no emprego, uma estratégia utilizada pela instituição para aglutinar o maior número de sócios matriculados foi a flexibilização do programa do curso. Assim, para o aluno que não pudesse frequentar as aulas todos os dias da semana, era possível a matrícula em matérias isoladas. Porém, como forma de incentivá-lo a cursar todo o programa, se o aluno optasse pelas disciplinas isoladas, era cobrado dele o valor de cada disciplina separadamente, o que resultaria em um montante bem acima do valor da mensalidade para cursar todas as matérias do programa.

Os alunos ainda poderiam cursar as matérias durante o ano e submeterem-se ao exame somente quando se considerassem aptos, podendo, inclusive, não realizar o exame. E tudo indica que a aprovação nesses exames era criteriosa, sendo que, em 1912, de 20 alunos que prestaram o exame na sede carioca, apenas 09 foram aprovados para ingressarem no segundo ano do Curso Comercial.

Essa possibilidade de cursar as matérias isoladas indica a valorização de um conhecimento utilitário que o aluno poderia adquirir através delas, seja isoladamente, seja em todo o programa. Assim, o aluno poderia, nessa perspectiva, cursar as disciplinas sem o objetivo de ter um certificado, podendo escolher aquelas que mais lhes seriam úteis no emprego. Isso era veiculado nos canais de informação da ACM como forma de inserir o trabalhador nas ações da Comissão Intelectual, o qual, mesmo não tendo a pretensão ou oportunidade de cursar todo o Curso Comercial, poderia participar de algumas disciplinas que o qualificariam para se ascender no emprego.

[...] daí a eliminação dos privilégios escolares, dos diplomas e dos títulos, deixando que cada qual procure o estudo pelo que ele tem de alto e digno, e não com o intuito subalterno da conquista de um pergaminho que the dê descabidas e injustas prerrogativas na 
competição social (CORRÊA, 1912 apud CURY, 2009, p. 726).

A flexibilização do acesso aos conteúdos de interesse do aluno estava presente nos debates educacionais, naquele momento, sendo incorporada na Reforma Rivadávia Corrêa, de 1911. A Associação Cristã de Moços, em 1898, já caracterizava o Curso Comercial como propagador de um conhecimento de utilidade prática. A procura de um diploma não deveria, para a instituição, ser o guia para se interessar pelo aprofundamento nos estudos mas, sim, para a compreensão da necessidade de se preparar em diferentes matérias, especialmente naquelas que: "[...] o moço precisa na sua vida comercial". O diploma seria uma consequência do caminho percorrido (ASSOCIAÇÃO CRISTÃ DE MOÇOS, 1898, p. 39).

\section{Considerações Finais}

As Associações Cristãs de Moços no Brasil foram espaços não escolares de formação. Guiadas pelo princípio de formar o "caráter cristão", lançaram-se na tarefa de promover o "bem físico" e "intelectual" e a "moral-religioso" dos sócios. A dimensão intelectual foi parte integrante do projeto acmista. No discurso da Associação, para receber tal formação, o indivíduo deveria controlar suas vontades "mundanas" assim como perceber a utilidade da instrução para o progresso pessoal, da instituição e da nação.

A oferta de ações que proporcionariam a formação intelectual - Ensino Primário, Curso Comercial, Curso Preparatório, Conferências Populares - foi realizada pela ACM em formatos singulares. Estratégias de convencimento foram utilizadas pela instituição como forma de atrair alunos, sendo especialmente ancoradas em argumentos relativos à utilização do tempo ocioso com coisas úteis, as quais poderiam proporcionar ao indivíduo a ascensão social. O Curso Comercial foi um importante eixo formativo na instituição.

A Comissão de Instrução foi essencial na construção de um projeto de formação das Associações Cristãs de Moços, no Brasil. Por meio do Curso Comercial, as ACMs contribuíam na preparação intelectual do associado e ainda o educavam para o controle das vontades, da racionalização do tempo, da necessidade de almejar a ascensão no emprego. As ACMs atuaram, dessa forma, como um lugar de preparação, formando o associado para o trabalho, para novos hábitos, comportamentos e sensibilidades de uma formação intelectual acmista.

\section{Notas}

$1 \mathrm{O}$ marco inicial toma como referência a implantação da ACM do Rio de Janeiro, em 1893. $\mathrm{Na}$ década de 1920, o movimento acmista no Brasil contava com quatro Associações implantadas, em fase de consolidação: Rio de Janeiro (1893), Porto Alegre (1901), São Paulo (1902) e Recife (1907). Ao se analisar as edições da revista Mocidade, encontra-se, a partir de 1924, uma ausência de informações referentes à sede de Recife. No mesmo sentido, na VII Convenção das ACMs no Brasil, realizada em 1929, não há sinais da presença da Associação Cristã de Moços de Recife. Dessa forma, mesmo sendo impreciso o fim das atividades da sede pernambucana, sua extinção revela um novo momento no projeto acmista brasileiro: fortalecia o investimento na consolidação das sedes existentes, abandonando, temporariamente, as iniciativas de implantação de novas sedes em outras regiões do Brasil. Dentre as ações da ACM no movimento de implantação da instituição no Brasil (1893-1929), tratamos nesse estudo da presença do Curso Comercial como uma ação central no projeto formador acmista, que apresenta como limite final o ano de $1929 \mathrm{em}$ decorrência da escassez de fontes que nos permitem tratar do período de consolidação das sedes existentes, a partir de 1929.

2 Para maiores informações sobre Curso Primário, Curso Preparatório, Aulas Avulsas, Biblioteca, Sala de Leitura, Conferências Populares e Grupos de Estudos, cf: Baía (2012).

3 O relatório da VII Convenção das ACMs do Brasil, publicado em 1929, ressalta que alguns alunos da ACM carioca foram aprovados no Colégio Pedro II.

4 Segundo o dicionário Aurélio, Estenografia é o mesmo que Taquigrafia, significando escrita abreviada e simplificada, na qual se empregam sinais que permitem escrever com a mesma rapidez com que se fala (FERREIRA, 2004). Já o Guarda-livros é um empregado do comércio, ou um profissional independente, que se encarrega da escrituração dos livros mercantis (FERREIRA, 2004).

5 O Relatório da ACM carioca apresentado na VII Convenção Nacional das ACMs, em 1929, mostra a presença do Curso Comercial, Preparatório e das 
Aulas avulsas acontecendo no período diurno, fato que indica a existência de um público variado, diferente daquele dos momentos anteriores, nos quais, por trabalharem durante o dia, os sócios necessitavam de estudar no período noturno.

6 Não encontrei indícios do programa curricular desses cursos nas fontes pesquisadas, possivelmente pela ausência da oferta deles em anos posteriores. Clark (1903) indica que a Comissão de Instrução era responsável por estudar as necessidades dos associados e estabelecer as classes daqueles assuntos que seriam da utilidade deles. Portanto, acredito que a criação ou a extinção de um curso pela Associação Cristã de Moços eram definidos pela demanda.

\section{Referências}

BAIA, A.C. Associação Cristã de Moços no Brasil: um projeto de formação intelectual, moral e física (1890-1929). 2012. 214f. Tese (Doutorado em Educação). Belo Horizonte: UFMG, 2012.

CERTEAU, M. A Escrita da História. Rio de Janeiro: Forense Universitária, 2006.

CURY, C.R.J. A desoficialização do Ensino no Brasil: A reforma Rivadávia. Revista Educação e Sociedade. Campinas, vol.30, $\mathrm{n}^{\mathrm{o}}$ 108, p. 717-738, 2009.

FERREIRA, A.B.H. Novo dicionário da Língua

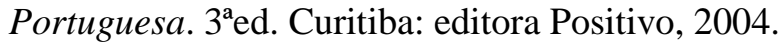

HOBSBAWN, E. Da revolução industrial inglesa ao imperialismo. $4^{\mathrm{a}} \mathrm{ed}$. Rio de Janeiro: ForenseUniversitária, 1986.

SOUZA, R.F. Demandas populares pela educação na Primeira República: aspectos da modernidade brasileira. Revista Educação e Filosofia. Uberlândia, 6 (12), jan-dez, p. 63-70, 1992.

THOMPSON, E. P. Os Românticos. Rio de Janeiro: Civilização Brasileira, 2002.

\section{Acervos e fontes pesquisados}

ASSOCIAÇÃO CRISTÃ DE MOÇOS. Modelo dos Estatutos de uma Associação Cristã de Moços do Rio de Janeiro. New York/Rio de Janeiro, 1893.

Associação Cristã de Moços do Rio de Janeiro: um esboço de sua história, dos seus objetivos, e dos seus métodos. Rio de Janeiro: Casa Publicadora Methodista, 1898.

Janeiro, 1910.

. Qual será o meu futuro? Rio de Ambicioso. 1911.

- Signaes de Progresso: Relatório do Trabalho da Associação Cristã de Moços do Rio de Janeiro: Anos de 1911-1912. Rio de Janeiro, 1912.

Vale quem tem. Rio de Janeiro, 1913.

. Mais dois anos de serviço à comunidade. Rio de Janeiro, 1916.

Pela Defesa Nacional: os primeiros 25 anos de serviço. Rio de Janeiro, 1918a.

de Janeiro, 1918b.

Pela pátria preparando as forças. Rio Relatório da VII Convenção das A.C.M. no Brazil. Rio de Janeiro, Comissão Nacional, 1929.

CLARK, M. Em prol da Mocidade: instruções sobre os trabalhos das Associações Cristãs de Moços. Rio de Janeiro: Casa editora presbiteriana, 1903.

REVISTA MOCIDADE, Rio de Janeiro, 18981925.

SOUZA, F. A regeneração nacional pelo indivíduo. (Conferências). Igreja Evangélica Fluminense, 1917. 


\section{Sobre os autores}

Anderson da Cunha Baía: Doutor em Educação - FAE/UFMG; Professor do curso de Educação Física da Universidade Federal de Viçosa; Membro do CEMEF/UFMG.

Andrea Moreno: Doutora em Educação - UNICAMP; Professora da graduação e pós-graduação - FAE/UFMG; Membro do GEPHE/UFMG e CEMEF/UFMG.

Recebido em fevereiro de 2016.

Aprovado em março de 2016. 